Note

\title{
Interactions between hairy rod anionic conjugated polyelectrolytes and nonionic alkyloxyethylene surfactants in aqueous solution: Observations from cloud point behaviour
}

\author{
Sofia M. Fonseca ${ }^{\mathrm{a}, *}$, M. Ermelinda Eusébio ${ }^{\mathrm{a}}$, Ricardo Castro $^{\text {a }}$, Hugh D. Burrows $^{\text {a }}$, \\ Maria José Tapia ${ }^{\mathrm{b}}$, Ulf Olsson ${ }^{\mathrm{c}}$ \\ a Departamento de Química, Universidade de Coimbra, 3004-535 Coimbra, Portugal \\ ${ }^{\mathrm{b}}$ Universidad de Burgos, Plaza Misael Bañuelos, 09001 Burgos, Spain \\ c Physical Chemistry 1, Center for Chemistry and Chemical Engineering, Lund University, P.O. Box 124, SE-221 00 Lund, Sweden
}

Received 20 April 2007; accepted 3 July 2007

Available online 10 July 2007

\begin{abstract}
The effect of three anionic, hairy-rod fluorene based conjugated polyelectrolytes on the cloud points of the alkyloxyethylene surfactants $\mathrm{C}_{10} \mathrm{E}_{3}$, $\mathrm{C}_{12} \mathrm{E}_{4}, \mathrm{C}_{12} \mathrm{E}_{5}$, and $\mathrm{C}_{12} \mathrm{E}_{6}$ has been studied in aqueous solution. Although the association behaviour of these rigid polymers with surfactants is different from that of more flexible polyelectrolytes, both types of polymers are seen to increase the cloud points, probably as a consequence of associative interactions. The possible importance of Coulombic interactions is suggested by the decrease in cloud points with these systems in the presence of $\mathrm{NaCl}$. With the conjugated polyelectrolytes, the effect appears to be most pronounced with poly[9,9-bis(4-phenoxybutylsulfonate)fluoreneco-2,5-thienylene], which may result from specific interactions between oxyethylene groups and the thiophene ring. The value of cloud point behaviour in designing water based formulations for preparation of devices of these conjugated polyelectrolytes is discussed.
\end{abstract}

(c) 2007 Elsevier Inc. All rights reserved.

Keywords: Conjugated polyelectrolytes; Nonionic surfactants; Cloud points

\section{Introduction}

There is considerable interest in water soluble conjugated polyelectrolytes as chemical and biological sensors [1-7], and as components of light emitting diodes (LEDs) or other molecular electronic devices [8]. They also undergo self-assembly with oppositely charged species, such as surfactants, to build up complex multilayer structures, with potentially interesting materials properties [9]. Further, with the development of solvent based methodologies, such as inkjet printing [10], for the preparation of high resolution thin film molecular devices involving conjugated polymers there is a need for good water-based formulations containing them.

Fluorene based polymers and copolymers are particularly valuable for these applications as they have high fluorescence

\footnotetext{
* Corresponding author. Fax: +351 239827703.

E-mail address: sfonseca@qui.uc.pt (S.M. Fonseca).
}

quantum yields and blue emission [11], making them very suitable for use in LEDs. In addition, they can form aligned liquid crystalline structures, leading to possibilities of polarised light emission [11].

However, conjugated polyelectrolytes tend to form clusters in aqueous solution $[1,3,9,12,13]$, which reduce fluorescence quantum yields. This becomes a particularly serious problem with fluorene copolymers $[3,4,12,13]$ and poly ( $p$-phenylene) based polyelectrolytes [14]. These are classed as "hairy-rod" polymers, having a rigid backbone surrounded by flexible sidechains, and are of interest for both theoretical and practical reasons [15]. It is possible to break up the aggregates by adding an organic co-solvent [8] or an appropriate surfactant $[12,13]$. Nonionic surfactants, such as $n$-dodecylpentaoxyethylene glycol ether $\left(\mathrm{C}_{12} \mathrm{E}_{5}\right)[12,13]$, are particularly promising in this respect. With the anionic conjugated polyelectrolyte poly\{1,4-phenylene-[9,9-bis(4-phenoxybutylsulfonate)]fluorene-2, 7-diyl (PBS-PFP), it is only possible to form a metastable dis- 
persion of polymer agglomerates by stirring in water. However, these are broken up to give stable solutions on addition of $\mathrm{C}_{12} \mathrm{E}_{5}$ $[12,13]$, or other alkyloxyethylene surfactants at concentrations above the surfactant critical micelle concentration. However, the structures of these aggregates of surfactants with the rigid rod conjugated polyelectrolytes are very different from those of more flexible polyelectrolytes or water soluble polymers, where a "pearl necklace" structure is normally thought to be formed at surfactant concentrations (critical aggregation concentrations) considerably below the surfactant $\mathrm{cmc}$ [16]. Small angle neutron scattering (SANS) studies [13], coupled with NMR measurements [17], suggest that this results from incorporation of PBS-PFP as isolated chains into long, wormlike micelles.

Nonionic surfactants containing polyoxyethylene chains (designated $\mathrm{C}_{n} \mathrm{E}_{m}$, where $n$ and $m$ are the chain lengths of alkyl and oligooxyethylene chains, respectively) themselves show interesting aggregation behaviour in the presence of water leading to complicated binary and ternary phase diagrams $[16,18-20]$. Of particular relevance to the present polymer systems is the existence of a so-called cloud point temperature, below which there is a homogeneous micellar solution [16] while at higher temperatures, phase separation into one surfactant-rich and one surfactant-poor liquid phase occurs. The onset of phase separation is manifested by a cloudiness of the solutions, although the actual phase behaviour may be fairly complex and may correspond to formation of various two-phase or one-phase systems [21]. Cosolutes can either decrease or increase the cloud points of aqueous $\mathrm{C}_{n} \mathrm{E}_{m}$ systems [16]. The study of the effect of third components on cloud points provides a simple method for obtaining information on interaction between the surfactant and cosolute. We report the effect of three hairy rod, anionic fluorene based conjugated polyelectrolytes on the cloud points of $\mathrm{C}_{10} \mathrm{E}_{3}, \mathrm{C}_{12} \mathrm{E}_{4}, \mathrm{C}_{12} \mathrm{E}_{5}$, and $\mathrm{C}_{12} \mathrm{E}_{6}$ in water.

\section{Experimental}

The three conjugated polyelectrolytes poly $\{1,4-$ phenylene[9,9-bis(4-phenoxybutylsulfonate)]fluorene-2,7-diyl \} (PBSPFP, $M_{\mathrm{n}} \approx 6500 \mathrm{~g} \mathrm{~mol}^{-1}$ ), poly [9,9-bis(4-phenoxybutylsulfonate)fluorene-co-2,5-thienylene] $\left(1 \mathrm{~T}, M_{\mathrm{n}} \approx 3500 \mathrm{~g} \mathrm{~mol}^{-1}\right)$, and poly[9,9-bis(4-phenoxybutylsulfonate)fluorene-co-2, $2^{\prime}$-bithiophene] $\left(2 \mathrm{~T}, M_{\mathrm{n}} \approx 3300 \mathrm{~g} \mathrm{~mol}^{-1}\right.$ ) were kind gifts from Professor Scherf and Dr. Pradhan, and were used without further treatment. Their structures are given in Fig. 1, while the syn- thesis and photophysical properties have been described elsewhere $[12,22]$. Pure $n$-decyltrioxyethylene glycol ether $\mathrm{C}_{10} \mathrm{E}_{3}$, $n$-dodecyltetraoxyethylene glycol ether $\mathrm{C}_{12} \mathrm{E}_{4}, n$-dodecylpentaoxyethylene glycol ether $\mathrm{C}_{12} \mathrm{E}_{5}$, and $n$-dodecylhexaoxyethylene glycol ether $\mathrm{C}_{12} \mathrm{E}_{6}$ were obtained from Nikko and used without further treatment. Their structures are also given in Fig. 1. Experiments were also carried out with $\mathrm{C}_{12} \mathrm{E}_{5}$ obtained from Fluka and gave similar results. However, with $\mathrm{C}_{12} \mathrm{E}_{4}$ from Sigma (Brij 30), although qualitatively similar results were obtained, differences were observed in the cloud point behaviour, probably due to the presence of other alkyloxyethylene surfactants. Sodium bis(2-ethylhexyl)sulfosuccinate (Aerosol OT or AOT) was purchased from Fluka.

Conventionally, cloud points are measured by heating a $1 \%$ aqueous surfactant solution to above clouding and then monitoring the transition from turbid to clear solution on slow cooling of the sample [16]. Because only small quantities of the polymer were available, the effect of the polymer on the cloud points of the surfactants was studied using hot-stage microscopy. Cloud points of all surfactant solutions were determined by visual inspection through a Leica DMRB polarising microscope connected to a Sony image processing equipment composed of CCD-IRIS/RGB video camera, DVD recorder and video monitor. Hot stage video microscopy analysis was performed using a Linkam system DSC 600 equipped with a liquid nitrogen pump. For image analysis, a Linkam system software with Real Time Video Measurement System was used. A small amount of the surfactant solution was placed in a 7-mm diameter glass crucible used as cell, which was covered with a glass lid. The samples were heated and cooled at a scanning rate of $1{ }^{\circ} \mathrm{C} / \mathrm{min}$. As will be seen in the next section, values obtained by this technique for binary surfactant-water systems are in excellent agreement with those in the literature. Surprisingly, the system with $\mathrm{C}_{10} \mathrm{E}_{3}$ did not freeze under these conditions, although the cloud point is below $0{ }^{\circ} \mathrm{C}$. Freezing was observed at faster heating rates. The origins of this interesting phenomenon are under further investigation.

Fluorescence spectra were recorded on a Jobin-Yvon SPEX Fluorolog 3-22 spectrometer and were corrected for the wavelength response of the system.

\section{Results and discussion}

Samples of the four surfactants in water were studied by video microscopy on the hot stage of a microscope. Upon heat-

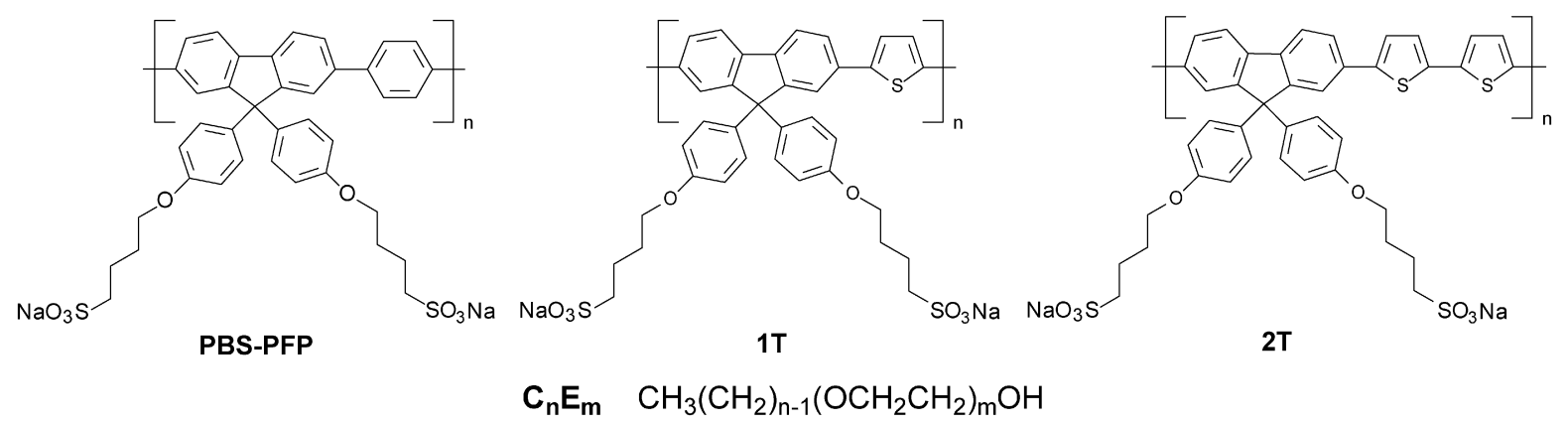

Fig. 1. Structures of conjugated polyelectrolytes and surfactants used. 
ing, phase separation was observed. Cloud points obtained by this technique were in excellent agreement with literature data. For example, the cloud point for $1 \% \mathrm{w} / \mathrm{w}_{12} \mathrm{C}_{5}$ is $30.8^{\circ} \mathrm{C}$, which is in good agreement with literature values $\left(31.9^{\circ} \mathrm{C}\right.$ [19], $31.3^{\circ} \mathrm{C}$ [23], $32.5^{\circ} \mathrm{C}$ [24], and $31.8^{\circ} \mathrm{C}$ [25]). The effect of anionic conjugated polyelectrolytes on the cloud point was studied using solutions of $1 \% \mathrm{w} / \mathrm{w} \mathrm{C}_{12} \mathrm{E}_{5}$ in the presence of $0.1 \mathrm{~g} / \mathrm{L}$ PBS-PFP, 1T, and 2T. In all cases, an increase in the cloud point was observed, with values $33.0,37.6$, and $35.6^{\circ} \mathrm{C}$, respectively at these concentrations. The effect of a conventional additive, the alkylsulfonate Aerosol OT or AOT, was also studied at similar $\mathrm{mol} / \mathrm{mol}$ ratio. In the presence of AOT, in which strongly associative interactions are expected, the cloud point of $\mathrm{C}_{12} \mathrm{E}_{5}$ increased to $35.7^{\circ} \mathrm{C}$. This is very similar to what is observed with $1 \mathrm{~T}$ and $2 \mathrm{~T}$.

SANS studies with PBS-PFP and $\mathrm{C}_{12} \mathrm{E}_{5}$ suggest a growth of wormlike structures on increasing surfactant/polymer ratio [13]. For two of the conjugated polyelectrolytes (1T and PBS-PFP), the dependence of clouding temperature on the polymer concentration $(0.02-0.2 \mathrm{~g} / \mathrm{L})$ was also studied at a constant $\mathrm{C}_{12} \mathrm{E}_{5}$ concentration $(1 \% \mathrm{w} / \mathrm{w})$. The cloud points of the solutions are plotted in Fig. 2a against the polymer concentrations. At low concentrations $(\leqslant 0.15 \mathrm{~g} / \mathrm{L})$ a roughly linear relationship was obtained between cloud point and polymer concentration. With PBS-PFP the increase in cloud point was small. However, a stronger increase in cloud point with polymer concentration was observed with $1 \mathrm{~T}$, which was particularly marked at high polymer concentrations $(>0.16 \mathrm{~g} / \mathrm{L})$. Fig. $2 \mathrm{~b}$ shows the effect of adding $\mathrm{NaCl}$ to a $1 \%$ w/w $\mathrm{C}_{12} \mathrm{E}_{5}$ solution in the presence of $0.1 \mathrm{~g} / \mathrm{L}$ of the polymer $1 \mathrm{~T}$. Upon increasing the ionic strength, a decrease in cloud point was observed. Since salt is expected to screen electrostatic interactions, this may suggest a strong Coloumbic contribution to the associative interactions between the conjugated polyelectrolytes and nonionic surfactants.

The fluorescence spectra of a PBS-PFP solution with $1 \%$ $\mathrm{w} / \mathrm{w}_{12} \mathrm{E}_{5}$ were recorded at different temperatures, below and above the cloud point temperature of the surfactant, and are shown in Fig. 3. The spectra are very similar, only a small increase in intensity is observed upon increasing the temperature. As noted earlier [12], when the conjugated polymers are present as aggregates the emission is red shifted relative to that of isolated chains. This suggests that the copolymer remains inside the micelles as isolated chains when there is the phase separation into a surfactant rich and a surfactant poor solution.

Clouding was also studied of aqueous solutions of the nonionic surfactants $\mathrm{C}_{10} \mathrm{E}_{3}, \mathrm{C}_{12} \mathrm{E}_{4}$, and $\mathrm{C}_{12} \mathrm{E}_{6}$ in the presence of the same anionic conjugated polyelectrolytes. In all cases an increase in cloud point was observed in the presence of the polymers, with the most marked effects in all cases being with the thiophene containing copolymers $1 \mathrm{~T}$ and $2 \mathrm{~T}$. Data for all the systems studied are summarised in Table 1 .

It is well known that cloud points for nonionic surfactants are strongly dependent on cosolutes. Electrolytes may either increase or decrease the cloud point, following the Hofmeister series [26]. With salts, if the cosolute is enriched in the vicinity of the oxyethylene groups, the effect being domi-

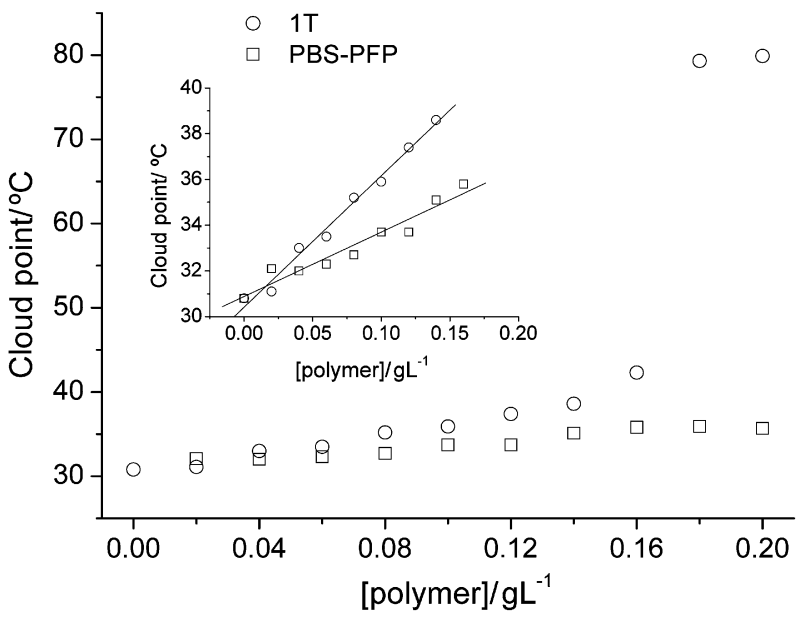

(a)

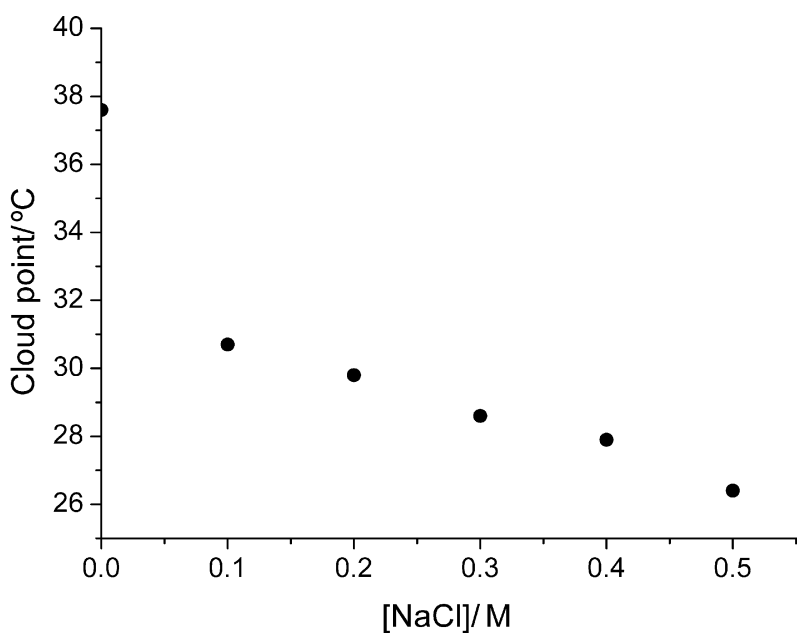

(b)

Fig. 2. (a) Cloud point of $\mathrm{C}_{12} \mathrm{E}_{5}(1 \% \mathrm{w} / \mathrm{w})$ vs conjugated polyelectrolyte (1T and PBS-PFP) concentration, (b) effect of $\mathrm{NaCl}$ on the cloud point of a $1 \% \mathrm{w} / \mathrm{w}$ $\mathrm{C}_{12} \mathrm{E}_{5}$ solution in the presence of $0.1 \mathrm{~g} / \mathrm{L} 1 \mathrm{~T}$.

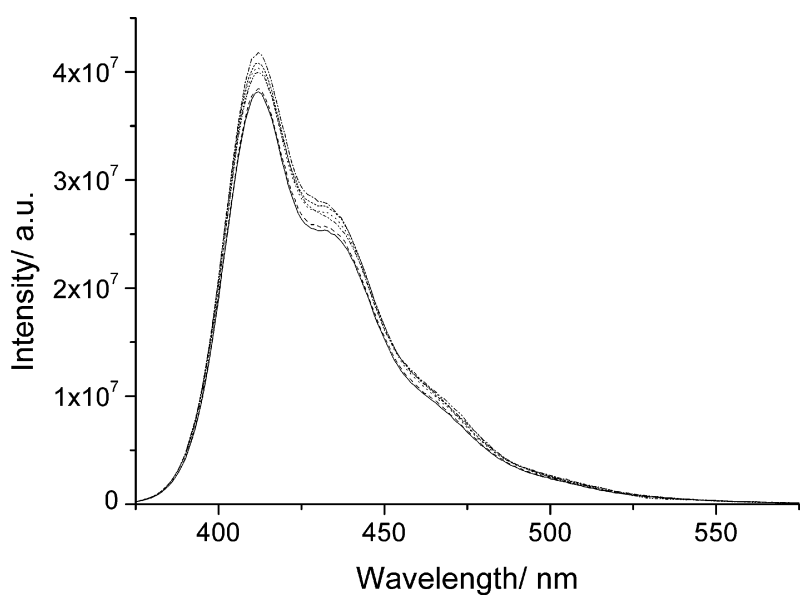

Fig. 3. Fluorescence spectra of a PBS-PFP solution $(5.69 \mathrm{mg} / \mathrm{L})$ with $1 \% \mathrm{w} / \mathrm{w}$ $\mathrm{C}_{12} \mathrm{E}_{5}$ at different temperatures $\left(25,29,30,31,32\right.$, and $\left.33^{\circ} \mathrm{C}\right)$. The fluorescence intensity slightly increases with temperature.

nated by the anions, increased solubility and an increased cloud point results. When the cosolute is depleted in the vicinity of the oxyethylene groups, the opposite is observed [26]. With 
Table 1

Cloud points $\left({ }^{\circ} \mathrm{C}\right.$ ) for $1 \% \mathrm{w} / \mathrm{w}$ solutions of nonionic surfactants in water alone and with $0.1 \mathrm{~g} / \mathrm{L}$ conjugated polyelectrolytes

\begin{tabular}{lccll}
\hline & $\mathrm{C}_{10} \mathrm{E}_{3}$ & $\mathrm{C}_{12} \mathrm{E}_{4}$ & $\mathrm{C}_{12} \mathrm{E}_{5}$ & $\mathrm{C}_{12} \mathrm{E}_{6}$ \\
\hline Water & -14.1 & 7.1 & 30.8 & 52.4 \\
PBS-PFP & -12.1 & 10.9 & 33.0 & 54.2 \\
$1 \mathrm{~T}$ & -7.4 & 18.2 & 37.6 & 60.5 \\
$2 \mathrm{~T}$ & -8.2 & 16.7 & 35.6 & 58.4 \\
\hline
\end{tabular}

$\mathrm{C}_{12} \mathrm{E}_{5} /$ poly(ethylene oxide) (PEO) mixtures, another type of interaction is found, and the observed decrease of the clouding temperature of $\mathrm{C}_{12} \mathrm{E}_{5}$ was explained by formation of micellar clusters within the PEO coil domains [24]. With nonionic surfactants in the presence of anionic polyelectrolytes, rather different behaviour has been reported [27-29]. The hydrophobically modified flexible polyelectrolyte poly(sodium acrylate) (HMPA) [27] increases the $\mathrm{C}_{12} \mathrm{E}_{5}$ cloud point due to surfactantpolyelectrolyte association, forming a charged, water soluble complex. A similar increase of the cloud point is observed when small amounts of ionic surfactant are added to the nonionic surfactant solution, and leads to charged micelles [30]. We believe that similar factors must be involved in the present systems with the hairy-rod polymers, even though changes in the conformation of the backbone must be fairly restricted, and that the effects on the cloud point are associated with the formation of mixed polymer-surfactant species. This is supported by smallangle neutron scattering (SANS) studies on the ternary system $\mathrm{C}_{12} \mathrm{E}_{5}-\mathrm{D}_{2} \mathrm{O}-\mathrm{PBS}-\mathrm{PFP}$, where it is suggested that mixed wormlike aggregates are formed between the charged copolymer and the surfactant [13]. Similar SANS results have been reported for short-chain nonionic amphiphilic poly ( $p$-phenylene)s in $\mathrm{D}_{2} \mathrm{O}$ solutions in the presence of alkyloxyethylene surfactants [31]. We believe that with all the anionic conjugated polyelectrolytes studied, the increase in the surfactant cloud point results from associative interactions between surfactant and polymer stabilizing the solution phase. This provides a good route for solubilizing these conjugated polyelectrolytes using low concentrations of surfactants (for $\mathrm{C}_{12} \mathrm{E}_{5} \geqslant 50 \mu \mathrm{M} \approx 0.002 \mathrm{wt} \%$ ) [12].

A variety of hydrophobic and electrostatic interactions are involved in the aggregation behaviour of these conjugated polyelectrolytes [32]. In explaining the differences in effectiveness of the three conjugated polyelectrolytes on increasing the surfactant cloud point, all of these may be involved. Although with the relatively low molecular weight oligomers used it is impossible to completely rule out contributions to the observed behaviour from impurities, or from some influence of differences in polymer molecular weights or polyelectrolyte charges, the fact that a more pronounced effect of the copolymers on the cloud points is observed when they contain the relatively polar [33] thiophene moieties (1T and $2 \mathrm{~T}$ ) compared with the 1,4-phenylene derivative PBS-PFP may imply stronger association with the former compounds. It is known that thiophene rings take part in specific solute-solvent interactions [33], and we suggest that the more marked effect of $1 \mathrm{~T}$ and $2 \mathrm{~T}$ on cloud points may be partially due to such an interaction.

\section{Conclusions}

We have studied the effect of three anionic fluorene based conjugated polyelectrolytes on the cloud points of four nonionic alkyloxyethylene surfactants. In designing formulations based on these systems for thin film device preparation using printing technologies, the cloud point behaviour indicates that temperature may have a crucial influence on morphology. For preparation of homogeneous films, e.g., for optical applications, it will be best to work below the cloud point. However, it is known $[34,35]$ that electrical conductivity of conjugated polymer films may increase when particles are present. For these applications, it may be of interest to prepare films using surfactant/conjugated polyelectrolyte/water systems above the cloud point. Future experiments will be designed to test this.

\section{Acknowledgments}

We wish to acknowledge the valuable comments of the Reviewers of the original version of this manuscript, which we believe has helped clarify the interpretation of our results. We are indebted to Professor U. Scherf and Dr. S. Pradhan (Bergische Universität Wuppertal) for the gift of the three conjugated polyelectrolytes. One of us (S.M.F.) is grateful to the FCT for the award of a postdoctoral fellowship. We thank POCI/FCT/FEDER for financial support through the project POCI/QUI/58291/2004 and MEC and FEDER through the project MAT2004-03827. We are grateful for further funding for this collaboration through MEC/CRUP (Acções Integradas) and COST Action. Universidad de Burgos is also thanked for financial support of a short stay of M.J.T. in Coimbra University. U.O. thanks the Swedish Research Council (VR) for financial support.

\section{References}

[1] L. Chen, D.W. McBranch, H.-L. Wang, R. Helgeson, F. Wudl, D.G. Whitten, Proc. Natl. Acad. Sci. 96 (1999) 12287.

[2] C. Fan, K.W. Plaxco, A.J. Heeger, Trends Biotechnol. 23 (2005) 186.

[3] S.J. Dwight, B.S. Gaylord, J.W. Hong, G.C. Bazan, J. Am. Chem. Soc. 126 (2004) 16850.

[4] B. Liu, G.C. Bazan, Chem. Mater. 16 (2004) 4467.

[5] M.R. Pinto, K.S. Schanze, Synth. Stuttgart 9 (2002) 1293.

[6] G.D. Joly, L. Geiger, S.E. Kooi, T.M. Swager, Macromolecules 39 (2006) 7175.

[7] I.-B. Kim, A. Dunkhorst, J. Gilbert, U.H.F. Bunz, Macromolecules 38 (2005) 4560.

[8] W. Ma, P.K. Iyer, X. Gong, B. Liu, D. Moses, G.C. Bazan, A.J. Heeger, Adv. Mater. 17 (2005) 274.

[9] G. Decher, Science 277 (1997) 1232

[10] B.-J. de Gans, P.C. Duineveld, U.S. Schubert, Adv. Mater. 16 (2004) 203.

[11] U. Scherf, E.J.W. List, Adv. Mater. 14 (2002) 477.

[12] H.D. Burrows, V.M.M. Lobo, J. Pina, M.L. Ramos, J. Seixas de Melo, A.J.M. Valente, M.J. Tapia, S. Pradhan, U. Scherf, Macromolecules 37 (2004) 7425.

[13] M. Knaapila, L. Almásy, V.M. Garamus, S. Pradhan, C. Pearson, M.C. Petty, U. Scherf, H.D. Burrows, A.P. Monkman, J. Phys. Chem. B 110 (2006) 10248.

[14] M. Bockstaller, W. Köhler, G. Wegner, D. Vlassopoulos, G. Fytas, Macromolecules 34 (2001) 6359.

[15] M. Knaapila, R. Stepanyan, B.P. Lyons, M. Torkeli, A.P. Monkman, Adv. Funct. Mater. 16 (2006) 599. 
[16] K. Holmberg, B. Jönsson, B. Kronberg, B. Lindman, Surfactants and Polymers in Aqueous Solutions, second ed., Wiley, New York, 2003.

[17] H.D. Burrows, V.M.M. Lobo, J. Pina, M.L. Ramos, J. Seixas de Melo, A.J.M. Valente, M.J. Tapia, S. Pradhan, U. Scherf, S.I. Hintschich, C. Rothe, A.P. Monkman, Colloids Surf. A 270-271 (2005) 61.

[18] D.J. Mitchell, G.J.T. Tiddy, L. Waring, T. Bostock, M.P. McDonald, J. Chem. Soc. Faraday Trans. 1 (79) (1983) 975.

[19] R. Strey, R. Schomäcker, D. Roux, F. Nallet, U. Olsson, J. Chem. Soc. Faraday Trans. 86 (1990) 2253.

[20] U. Olsson, H. Wennerström, Adv. Colloid Interface Sci. 49 (1994) 113.

[21] C.A. Leng, F.J. Leng, G.J.T. Tiddy, Chem. Phys. Lett. 137 (1987) 188.

[22] S. Pradhan, Ph.D. thesis, Bergische Universität Wuppertal, Germany, 2004.

[23] J. Dong, G. Mao, Langmuir 16 (2000) 6641.

[24] E. Feitosa, W. Brown, P. Hansson, Macromolecules 29 (1996) 2169.

[25] U. Menge, P. Lang, G.H. Findenegg, J. Phys. Chem. B 103 (1999) 5768.

[26] A. Kabalnov, U. Olsson, H. Wennerstrom, J. Phys. Chem. 99 (1995) 6220.
[27] I. Iliopoulos, U. Olsson, J. Phys. Chem. 98 (1994) 1500.

[28] A. Sarrazin-Cartalas, I. Iliopoulos, R. Audebert, U. Olsson, Langmuir 10 (1994) 1421.

[29] E.Z. Radlinska, T. Gulik-Krzywicki, F. Lafuma, D. Langevin, W. Urbach, C.E. Williams, J. Phys. II France 7 (1997) 1393.

[30] P.-G. Nilsson, B. Lindman, J. Phys. Chem. 88 (1984) 5391

[31] T. Fütterer, T. Hellweg, G.H. Findenegg, J. Frahn, A.D. Schlüter, Macromolecules 38 (2005) 7451.

[32] H.D. Burrows, M.J. Tapia, C.L. Silva, A.A.C.C. Pais, S.M. Fonseca, J. Pina, J. Seixas de Melo, Y. Wang, E.F. Marques, M. Knaapila, A.P. Monkman, V.M. Garamus, S. Pradhan, U. Scherf, J. Phys. Chem. B 111 (2007) 4401.

[33] M. Fall, J.-J. Aaron, M.M. Dieng, C. Párkányi, Polymer 41 (2000) 4047.

[34] A.G. McDiarmid, A.J. Epstein, Faraday Discuss. Chem. Soc. 88 (1989) 317.

[35] A.P. Marques, C.M.A. Brett, H.D. Burrows, A.P. Monkman, B. Retimal, J. Appl. Polym. Sci. 86 (2002) 2182. 